\title{
The Ross procedure using autologous support of the pulmonary autograft: Techniques and late results
}

\author{
Peter D. Skillington, FRACS, ${ }^{\text {a,b,d }}$ M. Mostafa Mokhles, PhD, MSc, ${ }^{c}$ Johanna J. M. Takkenberg, MD, PhD, ${ }^{c}$ \\ Marco Larobina, FRACS, ${ }^{\mathrm{a}, \mathrm{b}, \mathrm{d}}$ Michael O'Keefe, FRACS, ${ }^{\mathrm{a}}$ Rochelle Wynne, PhD, MEd, ${ }^{\mathrm{a}, \mathrm{e}}$ and \\ James Tatoulis, MD, FRACS ${ }^{\mathrm{a}, \mathrm{d}}$
}

Objectives: It is hypothesized that by performing radical aortic root manipulation and then autologous support
for the pulmonary autograft in the Ross procedure, this will maintain aortic root size and should, in turn, lead to
the demonstrated low incidence of late aortic regurgitation and need for reoperation on the aortic root and valve.

\begin{abstract}
Methods: Aortic root size was measured echocardiographically both preoperatively and then at second yearly intervals in 322 consecutive patients who underwent a Ross operation between October 1992 and June 2013 with autologous support of the pulmonary autograft root using the patient's own aorta. This technique, a variant of the inclusion cylinder method, has been developed with the aim of minimizing prosthetic materials in the aortic root.

Results: Measures to reduce aortic root size included annulus reduction in 201 patients $(62.4 \%)$ and reduction in aortic sinus or sinotubular junction in 159 patients $(49.4 \%)$. Maximal aortic root diameter postoperatively at 5, 10 , and 15 years was 34.0,34.6, and $34.7 \mathrm{~mm}$, respectively. Eleven reoperations were required during the study period for progressive aortic regurgitation (none for aortic root enlargement), with freedom from reoperation being $96 \%$ at both 15 years and 18 years. Preoperative pure aortic regurgitation, aortic annulus, and sinotubular junction enlargement were risk factors for reoperation.
\end{abstract}

Conclusions: This inclusion method of pulmonary autograft implantation leads to minimal increases in aortic root size over time, with no reoperations for aortic root dilatation and a low requirement for aortic valve reoperation. The Ross procedure deserves to remain on the surgical menu for aortic valve replacement. (J Thorac Cardiovasc Surg 2015;149:S46-52)

See related commentary on pages S53-4.

The technique for inserting the pulmonary autograft (PA) during the Ross procedure (RP) has been shown to be an important determinant of long-term PA function and therefore a key factor in the avoidance of long-term reoperation. ${ }^{1-3}$ A myriad of Ross operative techniques have evolved to stabilize the aortic root geometry and prevent PA dilatation and the subsequent development of aortic regurgitation (AR), a common mode of late RP failure. ${ }^{4-6}$

From the Department of Cardiothoracic Surgery, ${ }^{\text {a }}$ Royal Melbourne Hospital, Melbourne, Australia; Department of Cardiothoracic Surgery, ${ }^{\mathrm{b}}$ Epworth Hospital, Melbourne, Australia; Department of Cardiothoracic Surgery, ${ }^{\mathrm{c}}$ Erasmus University Medical Center, Rotterdam, The Netherlands; Department of Surgery, ${ }^{\mathrm{d}}$ University of Melbourne, Parkville, Australia; and Department of Nursing, ${ }^{\text {e University of }}$ Melbourne, Parkville, Australia.

This study was funded by the Ross Procedure and Cardiac Surgery Trust.

Disclosures: Authors have nothing to disclose with regard to commercial support.

Read at The American Association for Thoracic Surgery Aortic Symposium, New York, New York, April 24-25, 2014.

Received for publication April 8, 2014; revisions received Aug 17, 2014; accepted for publication Aug 23, 2014; available ahead of print Oct 16, 2014.

Address for reprints: Peter D. Skillington, FRACS, Royal Melbourne Hospital, Private Medical Centre, Suite 27, Level 4, Royal Parade, Parkville, Victoria 3050, Australia (E-mail: peter.skillington@mh.org.au).

$0022-5223 / \$ 36.00$

Copyright (c) 2015 by The American Association for Thoracic Surgery

http://dx.doi.org/10.1016/j.jtcvs.2014.08.068
The described autologous external support technique of the PA demonstrates superior long-term outcomes in patients suitable for the RP. ${ }^{7,8}$ Surgical techniques to rigorously remodel the diameter of the native aortic annulus, aortic root, and ascending aorta allow native aortic tissue to be used to create aortic geometry mirroring normal for the patient's size. ${ }^{7-10}$ The remodeled aortic root provides a durable external scaffold for the PA and has been shown to retain its geometry long term, ${ }^{8}$ preserving PA function and preventing autograft failure late into the second decade of follow-up.

The authors have investigated whether the well-known risk factors for PA failure, including presentation with AR, male gender, and aortic root enlargement, also applied to this technique. The described method of autologous support is explained in more detail, and the reasons for late autograft failure are explained.

\section{MATERIALS AND METHODS}

From October 1992 to the end of June 2013, 346 patients underwent aortic valve replacement (AVR) using the RP, and of these, the study group comprising 322 patients underwent a variant inclusion cylinder method, where the PA was inserted as a root replacement after tailoring the recipient aortic root and closing it back around the autograft to provide for long-term autologous support. The patient demographics are identical to those presenting in a previous study of 310 patients (up to June 2012) reported in $2013,{ }^{7}$ with only 12 additional patients undergoing operation in the last year. Likewise, operative data pertaining to aortic crossclamp and 


\section{Abbreviations and Acronyms \\ $\mathrm{AR}=$ aortic regurgitation \\ AS $=$ aortic stenosis \\ $\mathrm{AVR}=$ aortic valve replacement \\ $\mathrm{BAV}=$ bicuspid aortic valve \\ $\mathrm{PA}=$ pulmonary autograft \\ $\mathrm{RP}=$ Ross procedure \\ STJ $=$ sinotubular junction}

cardiopulmonary bypass times and concomitant procedures (outside aortic root and pulmonary root procedures) are fairly similar to those reported recently. ${ }^{7}$ To summarize, the mean age of patients was 39.5 years (limits, 15-63 years), 224 patients (69.6\%) were male, and presentation was with aortic stenosis (AS) in 149 patients (46\%), AS/AR in 70 patients $(22 \%)$, and AR in 103 patients $(32 \%)$. The ethics committee at the Royal Melbourne Hospital approved the study of these patients, and each individual patient gave informed consent for participation in this study. The operations were performed at the Royal Melbourne Hospital and affiliated hospitals.

The steps of the operation with regard to cardiopulmonary bypass, myocardial protection, and transverse aortotomy incision have been described..$^{7-10}$ After excising the aortic valve, measurements of the aortic annulus and sinotubular junction (STJ) are taken and cross-checked against those obtained from the intraoperative transesophageal echocardiogram. The important preparation of the aortic root to receive the PA is commenced with a vertical incision in the noncoronary sinus, extending from the transverse aortotomy incision down to the level of the aortic annulus. As shown in Table 1, a large proportion of patients (72\%) underwent reduction of the aortic annulus, aortic sinus, or STJ. A smaller number of patients $(23 \%$ or $7.1 \%)$ required aortic root enlargement, only 2 of these at all levels, to accommodate the PA root. Only 67 patients (21\%) had no procedure to reduce or enlarge the aortic root.

The aim of the aortic root preparation has been to reduce (predominantly) or expand the aortic root to achieve an aortic annulus and STJ that measures 24 to $26 \mathrm{~mm}$ in male patients and 22 to $24 \mathrm{~mm}$ diameter in female patients, with the final individual dimension depending on the patient's size, particularly height. The aortic root now acts as a scaffold or external support, within which the PA root is implanted. This allows for maximal PA leaflet coaptation distance and minimal risk of leaflet prolapse or restriction. As shown in Figure 1, for the common situation where there is enlargement of the aortic annulus, STJ, or both, partial excision of the noncoronary sinus takes place via a V- or wedge-shaped excision, or a quadrangular excision, depending on the measured annulus and STJ diameter. In younger patients with an elastic aorta, the STJ measured diameter is best obtained from the intraoperative prebypass transesophageal echocardiogram. The aortic annulus dimension is best obtained in the relaxed heart with the passage of obturator type sizes. It should be mentioned that if the prebypass STJ diameter is large (26-32 $\mathrm{mm})$, a simultaneous longitudinal resection of the ascending aorta is performed with vertical direct closure (tailoring aortoplasty) before the distal autograft anastomosis to help maintain long-term stable STJ dimensions postoperatively without the need for prosthetic material. The ascending aorta is replaced with a polyester tube graft if it exceeds $45 \mathrm{~mm}$ in male patients and $40 \mathrm{~mm}$ in female patients.

If the aortic annulus is reduced by a minor degree (1-3 $\mathrm{mm}$ in diameter) plication only and reinforcement with an external polyester band (Figure 2) will suffice; however, for larger reductions in diameter $(4-8 \mathrm{~mm})$, it is necessary to perform a maximum width excision of $10 \mathrm{~mm}$ of noncoronary sinus tissue at the annular level, detach the left coronary ostium from the aorta as a button, dissect down to the level of the aortic annulus externally, and place a $60 \%$ circumference polyester band (partial ring) around the aortic annulus for the region subtended by left and noncoronary sinuses to narrow the annulus. Figure 3 shows 3 different aortic root reduction possibilities, depending on the shape of the aortic root encountered at operation. For very large aortic roots where the STJ exceeds 32 to $34 \mathrm{~mm}$ in diameter, the resultant geometric mismatch between host aortic root and PA is too great to enable this method of PA implantation. However, aortic annulus diameters as much as $38 \mathrm{~mm}$ have been repaired, providing the STJ does not exceed $32 \mathrm{~mm}$.

The authors believe it is imperative, when possible, to allow for frequent immersion of the PA in blood at all stages of the procedure (ie, before explant) while awaiting implantation in the right pericardial well, and during implantation by switching the left ventricular vent off frequently, so that the PA leaflets can remain nourished with blood during this rather prolonged operation. This may help retain optimum viability and cellular integrity. Optimum care should be taken to avoid kinking the coronary arteries as they are brought inside the aortic root and anastomosed to the PA sinuses. After the aortic crossclamp is released at the end of the procedure, it is imperative to check that both coronary arteries are exiting the aorta without kinking.

\section{Patient Follow-up}

All methods have been followed up with clinical review by the surgeon or cardiologist yearly, and follow-up echocardiograms have been obtained before hospital discharge, 6 to 12 months after operation, and thereafter at second yearly intervals unless otherwise clinically indicated.

\section{Statistical Methods}

Statistical analysis of clinical end points and their risk

factors. Patient survival was estimated using the Kaplan-Meier method. ${ }^{11}$ To investigate independent risk factors for mortality and morbidity caused by autograft failure, the Cox proportional hazard model was used. The number of aortic valve reoperations $(n=11)$ was insufficient to perform meaningful and reliable multivariable analysis. The risk factors that were found to correlate with aortic valve reoperation were obtained using univariate analyses. All statistical tests were 2-sided. All statistical analyses were performed using the Statistical Package for Social Sciences software, version 20.0 (SPSS, Inc, Chicago, Ill). GraphPad Prism 5.00 for Windows (GraphPad Software, La Jolla, Calif) was used to obtain life tables and corresponding Kaplan-Meier survival curves.

\section{Statistical Analysis of Longitudinal Data}

Continuous echocardiographic measurement. To assess the temporal trend of aortic sinus diameter over time after surgery, followup transthoracic echocardiographic measurements were analyzed longitudinally for change in mean response across time. ${ }^{12}$ A nonlinear longitudinal mixed model regression ${ }^{13,14}$ (SAS PROC NLMIXED; SAS Institute Inc, Cary, NC) was used to analyze these continuous repeated measurements.

Variable selection and risk factor analyses for continuous echocardiographic measurement. Patient characteristics, conduit properties, and procedure-related variables were screened for association with postoperative aortic sinus diameter. In addition, year of surgery (calculated as the time interval between first and last surgical procedure) and various transformations (eg, inverse, natural logarithm) of the available continuous variables were also screened as a potential risk factor.

Variable selection, with a $P$ value criterion for retention of variables in the model of .05 , used bootstrap bagging (bootstrap aggregation) ${ }^{13,15}$ This was a 4-step process. First, a patient was randomly selected from the original data set to begin a new data set. The original data set continued to be sampled until the new data set was $100 \%$ the size of the original. Second, risk factors were identified using automated forward stepwise selection. Third, results of the variable selection were stored. These 3 steps were repeated 1000 times. Finally, the frequency of occurrence of variables related to group membership was ascertained and indicated the reliability 
TABLE 1. Aortic root manipulations

\begin{tabular}{lrr}
\hline & No & $\%$ \\
\hline Aortic annulus reduction & & \\
Circumferential polyester ring & 17 & \\
Partial external polyester ring annuloplasty only & 95 & \\
Partial ring and annular plication in noncoronary sinus & 81 & \\
Annular plication only & 8 & 62.4 \\
Total & 201 & \\
Aortic sinus and STJ reduction & 59 & \\
Wedge excision and closure & 53 & \\
Quadrangular excision and closure & 25 & \\
Either of above with STJ polyester ring & 22 & \\
STJ ring only & 156 & 49.7 \\
Total & & \\
Aortic annulus enlargement & 2 & 0.6 \\
Manougian & & \\
Aortic sinus or STJ enlargement & 23 & 7.1 \\
Autologous pericardial patch & & \\
\hline STJ, Sinotubular junction. & &
\end{tabular}

of each variable (aggregation step). All variables with bootstrap reliability of $50 \%$ or greater were retained in the guided analysis.

Because of the limited capability of PROC NLMIXED to explore multivariable relations, we initially screened the variables using ordinary multivariable linear regression (PROC REG SAS) and the assumption of independence of observations with liberal entry criteria (0.2) and stay criteria (0.12). This analysis was performed simply to identify possible candidates for our repeated measurements model. These candidates and their transformations, if any, were entered at once into our model, and then eliminated one by one until all variables remaining had a $P$ value of .05 or less. Parametric estimates of continuous postoperative echocardiography measurements are accompanied by asymmetric $95 \%$ confidence limits, comparable to \pm 2 standard error, obtained by a bootstrap percentile method. ${ }^{16}$ The longitudinal analyses of echocardiographic data were performed using SAS9.2 (SAS Institute Inc).

\section{RESULTS}

\section{Early and Late Mortality}

There was 1 early death (within 30 days, after hospital discharge) due to myocardial infarction and 5 late deaths, at $3,4,5,10$, and 12 years postoperatively, due to noncardiovascular causes. Late actuarial survival at 20 years is
$97 \%$, previously shown to be equivalent to an age- and sex-matched Australian population. ${ }^{8}$ Follow-up is $97 \%$ complete (10 patients missing), and the mean follow-up period is 9.8 years encompassing 3225 patient years.

\section{Late Aortic Valve (Pulmonary Autograft) Reoperation}

There were 13 reoperations on the autograft, 11 for late progressive AR and none for AS. The other 2 reoperations were for endocarditis, in 1 of which the PA was preserved, with infection occurring in the external polyester ring implanted around the aortic root. Of the 11 reoperations for progressive late AR, 9 of the 11 patients initially presented with pure AR, 1 with AS, and 1 with mixed AS/AR. Significant postoperative AR had developed in all patients by 3 years after surgery, most within 12 months, with subsequent reoperation performed between 3 months and 7 years (mean, 4.1 years) later. All patients underwent AVR using a mechanical prosthesis. Analysis of autograft failure leading to redo AVR in these 11 patients reveals an identifiable technical failure in 10,6 of whom were of the initial 85 patients undergoing operation between 1992 and 1998. In 4 of these patients, significant aortic annulus dilatation was not corrected; these patients underwent operation between 1992 and 1996, before it was appreciated that the aortic annulus should be reduced to 24 to $26 \mathrm{~mm}$ in male patients and 22 to $24 \mathrm{~mm}$ in female patients. In 2 patients, the supracoronary ascending aorta was replaced with an oversized polyester graft $(28 \mathrm{~mm})$. In 4 patients, it is presumed that distortion of the autograft occurred during implantation, with subsequent early cusp prolapse leading to reoperation. There has been no evidence of macroscopic degeneration in any of the explanted PA valves. All resected valve leaflets were thin without focal thickening or nodule formation. They were not routinely sent for histologic analysis. There have been no aortic valve failures 7 years postoperatively. Freedom from aortic valve reoperation is $96 \%$ (95\% confidence interval, 92-98) at 18 years.

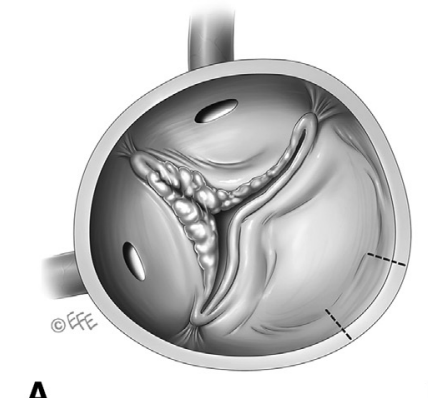

A

B

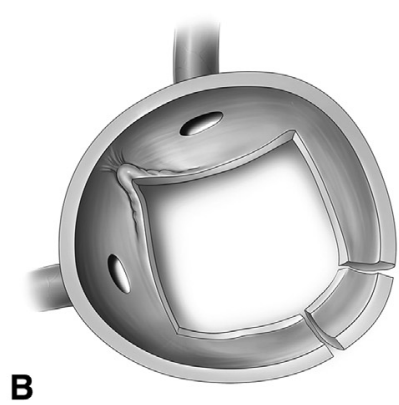

C

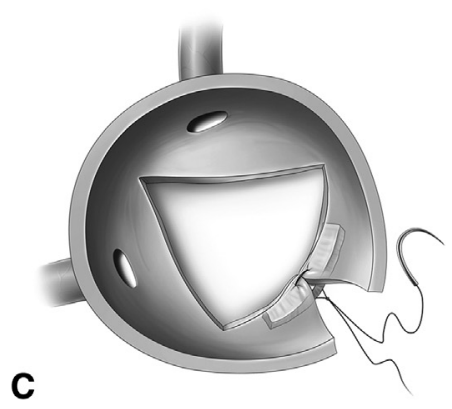

FIGURE 1. BAV, fused right/left coronary commissure, and enlarged aortic root. A, BAV before excision. B, Quadrangular excision of noncoronary sinus down to the level of the annulus to narrow the entire aortic root. C, Plication of the aortic valve annulus to narrow the aortic valve annulus. 


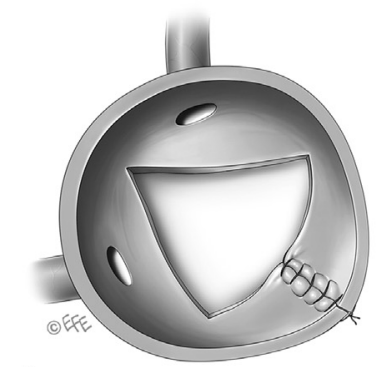

A

B

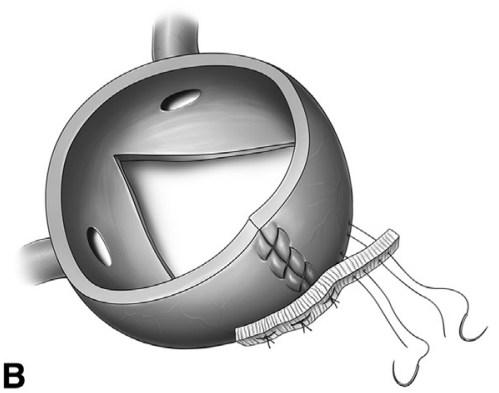

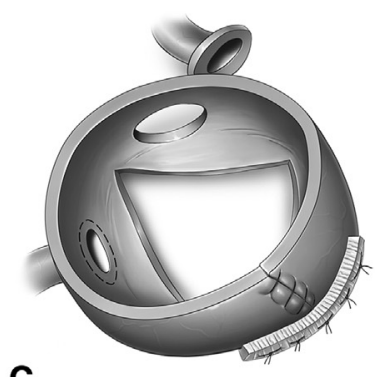

C

FIGURE 2. Repair of noncoronary sinus of aorta to narrow the entire aortic root. A, Direct suture repair of noncoronary sinus viewed from the inside. B, Multiple horizontal mattress sutures passed through the aortic annulus from inside to out, passed through a 4-mm-wide polyester band. C, Completion of aortic root repair and stabilization of aortic annulus reduction with external polyester ring.

\section{Risk Factors for Aortic Valve Reoperation}

Univariate analysis reveals that enlargement of the aortic annulus preoperatively $(P=.003)$, enlargement of the STJ $(P=.023)$, enlargement of the aortic sinus $(P=.003)$, and presentation with $\mathrm{AR}(P=.016)$ were risk factors for autograft reoperation. Age $(P=.240)$, gender $(P=.327)$, type of aortic annulus reduction, type of aortic root, and STJ modification and previous aortic valve surgery $(P=.95)$ were not significant risk factors. Minor variations in technique with respect to the distal autograft suture line were not significant predictors $(P=.47)$. There were insufficient reoperations to allow a meaningful multivariate analysis to be performed.

\section{Aortic Root Size Over Time}

As shown in Figure 4, there has been minimal increase in aortic root size over time, as measured by echocardiography. Fifteen years after surgery, the mean maximal aortic sinus diameter measures $34.7 \mathrm{~mm}$ ( $95 \%$ confidence interval, 34.1-35.3). The 15-year mean aortic root size varied according to presentation with AS $(33.5 \mathrm{~mm})$, AS/AR $(34.3 \mathrm{~mm})$, and AR $(36.8 \mathrm{~mm})$. Multivariate analysis
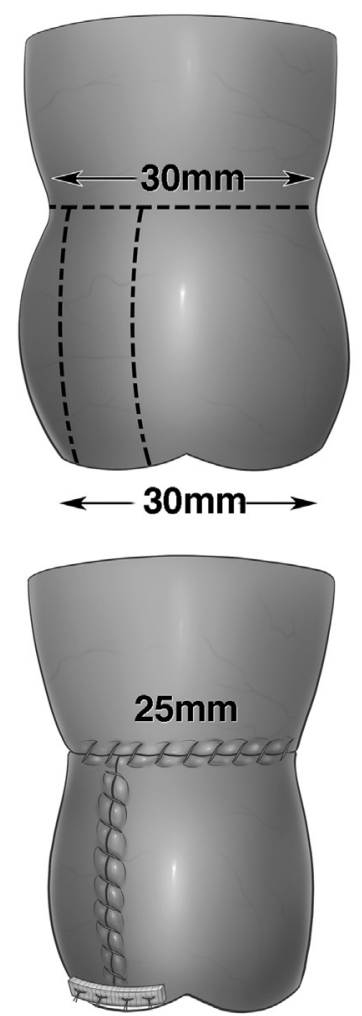

$25 \mathrm{~mm}$

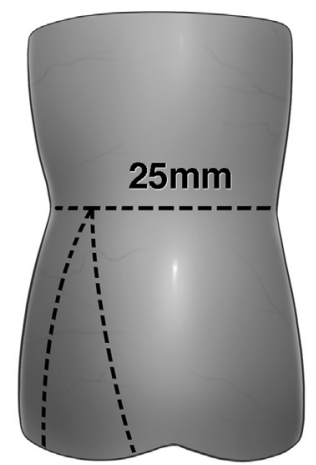

$32 \mathrm{~mm}$

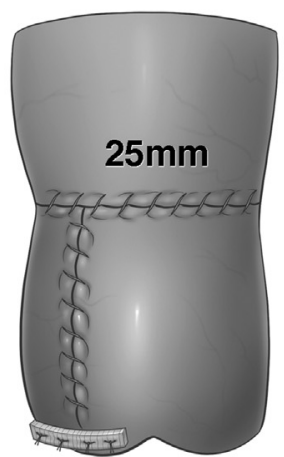

$25 \mathrm{~mm}$

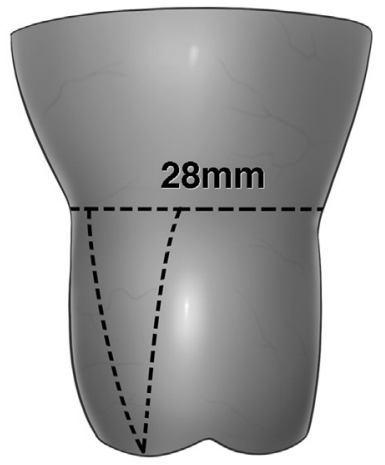

$25 \mathrm{~mm}$

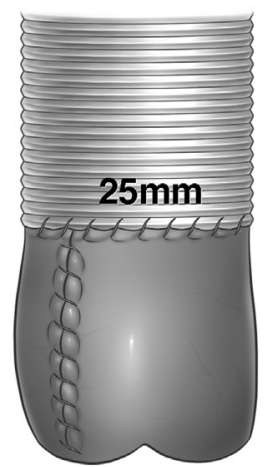

$25 \mathrm{~mm}$

FIGURE 3. Diagrammatic representation of narrowing aortic root, depending on pre-repair measurements of the aortic annulus and STJ. Three possible aortic root excisions are shown (pre-repair top, post-repair bottom). 


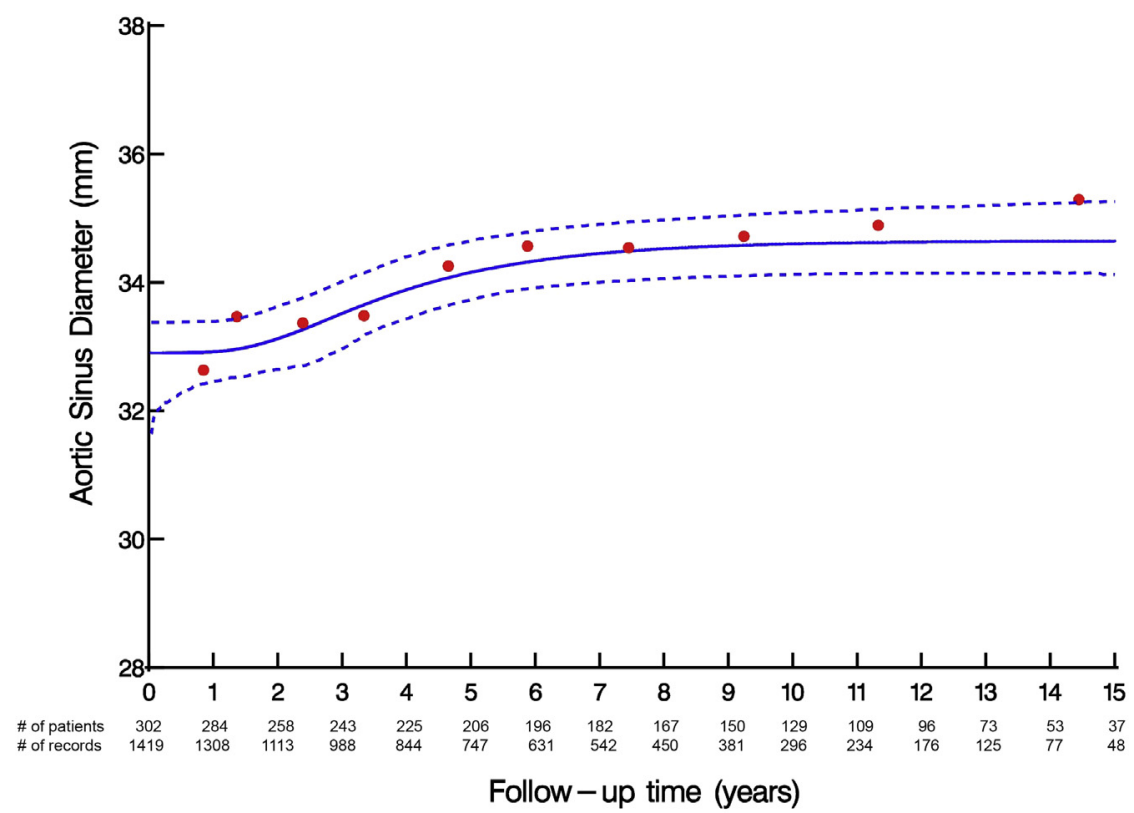

FIGURE 4. Temporal change in aortic sinus diameter; solid lines are parametric estimates of the mean aortic sinus diameter from the nonlinear longitudinal mixed model and are enclosed within dashed $95 \%$ bootstrap percentile confidence bands, equivalent to 2 standard deviations. Symbols represent crude estimates of grouped raw data without regard to repeated measures and are presented just to verify the model fitting.

reveals that independent risk factors for larger postoperative aortic root size include larger preoperative aortic sinus diameter $(P<.001)$, male gender $(P=.008)$, enlargement of the STJ at the time of surgery $(P=.044)$, and larger aortic annulus diameter at the time of surgery $(P=.006)$. AS (vs AR and AS/AR) is associated with a significantly smaller late aortic root size $(P=.010)$ (Table 2 and Figure 5). Of note, our bootstrap analysis indicated that the variable male has a reliability of only $20 \%$, indicating that although this variable was a significant predictor in our dataset, it might not be found as a predictor in other datasets of the same patients. There have been no reoperations for aortic root dilatation, and of 53 patients with echocardiography data to 15 years and more, only $5(1.5 \%$ of all patients) have developed a maximum aortic root size in excess of $40 \mathrm{~mm}$ in diameter, and none exceed $43 \mathrm{~mm}$.

TABLE 2. Risk factors associated with aortic sinus diameter during follow-up

\begin{tabular}{lccc}
\hline \multicolumn{1}{c}{ Factor } & Estimate \pm SE & $\boldsymbol{P}$ & Reliability \\
\hline $\begin{array}{l}\text { Preoperative aortic sinus } \\
\quad \text { diameter }\end{array}$ & $0.005195 \pm 0.001405$ & $<.001$ & $86 \%$ \\
Male (vs female) & $0.03776 \pm 0.01415$ & .008 & $20 \%$ \\
Autograft diameter & $0.01848 \pm 0.004579$ & $<.001$ & $100 \%$ \\
Enlargement of sinotubular & $0.04055 \pm 0.02006$ & .044 & $89 \%$ \\
$\quad$ diameter at the time of & & & \\
$\quad$ surgery & & & \\
Aortic annulus diameter & $0.006023 \pm 0.002162$ & .006 & $100 \%$ \\
AS (vs AR and AR/AS) & $-0.02847 \pm 0.01099$ & .010 & $91 \%$ \\
\hline
\end{tabular}

$A R$, Aortic regurgitation; $A S$, aortic stenosis; $S E$, standard error.

\section{DISCUSSION}

The RP has evolved considerably since first described by Donald Ross in 1967. ${ }^{17}$ Most of the technical evolution has centered around the PA implantation technique. The initial method was to implant the PA using a subcoronary technique. Apart from this method being difficult to perform for most surgeons, late failures do occur related to structural valve deterioration, predominantly leaflet prolapse, ${ }^{18}$ probably as a result of anatomic distortion during implantation of the PA unless it is inserted perfectly. The next method described was freestanding root replacement ${ }^{19,20}$; this technique is less demanding and similar to a modified Bentall procedure. Unfortunately, despite mostly guaranteeing early valve competence, this technique has suffered an even higher reoperation rate in most reported series $^{21-24}$ because of late aortic root dilatation often with concomitant development of increasing AR, with most reoperations occurring as patients enter the second decade of follow-up. Since then, an abundance of techniques have arisen to support the autograft, initially at the annular and STJ levels ${ }^{25-28}$ and more recently partial or complete support of the autograft root, with synthetic materials ${ }^{4-6}$ or autologous support, ${ }^{7,8}$ as practiced by our group. Beginning in 1992, 322 (or 93\%) of all patients receiving an RP at our institution have had this method used to support the autograft within the patient's own aorta, which has been adjusted mostly by reducing its size to act as a scaffold to prevent the autograft from dilating later. The authors believe this technique may be more reproducible because it involves inserting the PA as 


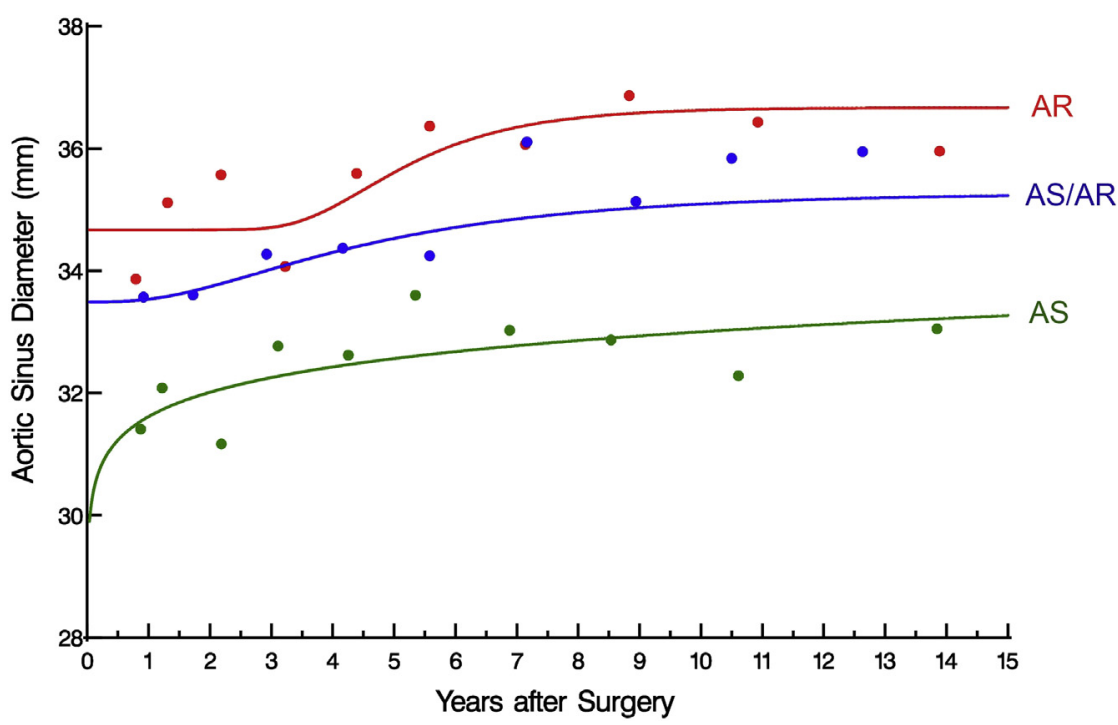

FIGURE 5. Solid lines are parametric estimates of the mean aortic sinus diameter after the RP from nonlinear longitudinal mixed model (AR group $=$ red, $\mathrm{AS}$ group $=$ green, $\mathrm{AR} / \mathrm{AS}$ group $=$ blue $).$ Symbols represent crude estimates of grouped raw data without regard to repeated measures and are presented just to verify the model fitting. $A R$, Aortic regurgitation; $A S$, aortic stenosis.

a root replacement, a technique most surgeons are familiar with. This means that the early advantages of using a root replacement, such as early valve competence, are retained. Prosthetic material use has been minimal with an external 4-mm-wide partial (predominantly) or fully circumferential external polyester ring used at the annular level in $60 \%$ of patients, and uncommonly a circumferential polyester ring used at the STJ (in 14.6\%).

The key technical point about this method of autologous support of the autograft, and where it fundamentally differs from all other inclusion type methods, is the degree of reduction of the aortic root performed, and the fact that the entire aortic root (including aortic sinus) is reduced in the majority of patients. Most other articles refer to the aortic annulus being reduced in diameter if it is 2 to $4 \mathrm{~mm}$ larger than the PA. ${ }^{1,26,28} \mathrm{We}$ always reduce the annulus or STJ if it is larger than $25 \mathrm{~mm}$ in male patients and 23 to $24 \mathrm{~mm}$ in female patients, regardless of the size of the PA. The autograft is so elastic, that obtaining an accurate size by use of a Hegar or other graded dilator is not possible in our experience. Thus, the aortic annulus and STJ diameters are reduced to 24 to $26 \mathrm{~mm}$ in male patients and 22 to $24 \mathrm{~mm}$ in female patients. This does not cause stenosis because the usual late mean aortic valve gradient is less than $5 \mathrm{~mm} \mathrm{Hg},{ }^{10}$ and it allows for excellent autograft leaflet coaptation. Better leaflet coaptation, preferably over distances exceeding $4 \mathrm{~mm}$, minimizes the risk that minor distortion of the autograft will result in more than trivial regurgitation. Another important and essential safety measure is to ensure that at the end of the procedure, the coronary arteries exit the aortic root in an unobstructed fashion. If the PA and external aortic root providing autologous support (which has been remodeled) do not line up, it is possible to kink the coronary arteries as they are anastomosed to the inner autograft cylinder. Preventing this occurrence also depends on commencing the distal autograft suture line above the left coronary anastomosis and including the proximal aorta in this suture line for at least $1 \mathrm{~cm}(\sim 15 \%)$ of the circumferential suture line.

There have been 11 failures of PA implantation, as evidenced by progressive postoperative AR leading to redo AVR. Seven failures occurred in the initial 84 patients undergoing operation between 1992 and 1998. Six of these failures almost certainly would not have occurred if current protocols had been followed. Four patients had an enlarged aortic annulus that was not reduced by annuloplasty, and 2 patients had the ascending aorta replaced with an oversized $28-\mathrm{mm}$ polyester graft, whereas currently a 22 - or $24-\mathrm{mm}$ graft (female patient) or a 24- or 26-mm graft (male patient) would be used. There have been no valve failures related to neoaortic root dilatation; these failures have been caused by valve distortion with leaflet prolapse. Of interest, all reoperations have been performed within 7 years (mean, 4.1 years) of the initial surgery, and there have been no late failures, once again suggesting that technical factors are the causative mechanism of failure. Conversely, if the autograft is implanted successfully, it tends to stay competent long-term. We have not seen any signs of macroscopic degeneration of the autograft at reoperation, suggested as a failure mechanism by others. ${ }^{28}$

Analysis of the aortic root size postoperatively using this method of support for the PA as measured by echocardiographically derived maximum aortic sinus diameter shows minimal enlargement with time. Perhaps the root-withinroot concept helps prevent aortic root dilatation with time, 
combined with aggressive root reduction that takes place at operation. The graph in Figure 4 shows the mean maximum aortic root size at 15 years is only $34.7 \mathrm{~mm}$, although this is significantly larger for patients presenting with AR and AS/ AR than those presenting with AS. Time will tell whether this group of patients with predominantly bicuspid aortic valve (BAV) will develop further aortic root enlargement 25 or 30 years postoperatively given the aortopathy that occurs with BAV, although this has not been seen in the cohort with 15 to 20 years of follow-up, with 70 patients in this category, 53 of whom had a recent echocardiogram. One potential area of weakness with this technique is that there is a small part of the autograft around each of the coronary ostial anastomoses that is not supported by the retained aortic root; however, there has been no aneurysmal enlargement seen on serial echocardiography. Also, the section of the aortic root most prone to late aneurysm formation is the noncoronary sinus, and with this technique the neononcoronary sinus of the autograft is fully supported.

\section{Study Limitations}

This study is predominantly a single surgeon experience that may not be generalizable, and the results may not be reproducible by others. Also, more than $90 \%$ of patients had congenital BAV disease, and thus many of the techniques reported may not be applicable to patients with predominantly other valve disease causes. However, in Western countries, BAV is the predominant valve cause encountered in those aged less than 60 years.

\section{CONCLUSIONS}

This method of autologous support of the PA during the $\mathrm{RP}$ uses radical remodeling of the entire aortic root, including the annulus, aortic sinus, and STJ, based on predetermined measurements using the patient's size and not the PA diameter measured at operation. This creates a scaffold within which a root replacement is performed with minimal distortion, using negligible prosthetic material. This has been shown to provide excellent long-term durability of aortic valve function with no significant increase in neoaortic root size during follow-up. The RP deserves to be higher on the list of surgical options for younger patients with AVR than where it currently resides.

The authors thank Tonia Iacuone for typing the article and Mardi Malone for assistance with submission of the article.

\section{References}

1. Brown JW, Ruzmetov M, Shahriari AP, Rodefeld MD, Mahomed Y, Turrentine MW. Modification of the Ross aortic valve replacement to prevent late autograft dilatation. Eur J Cardiothorac Surg. 2010;37:1002-7.

2. Charitos EI, Hanke T, Stierle U, Robinson DR, Bogers AJ, Hemmer W, et al. Autograft reinforcement to preserve autograft function after the Ross procedure: a report from the German-Dutch Registry. Circulation. 2009;120(11 Suppl): S146-54.
3. El-Hamamsy I, Eryigit Z, Stevens LM, Sarang Z, George R, Clark L, et al. Longterm outcomes after autograft versus homograft aortic root replacement in adults with aortic valve disease: a randomised controlled trial. Lancet. 2010;376: 524-31.

4. Juthier F, Banfi C, Vincentelli A, Ennezat PV, Le Tourneau T, Pinçon C, et al. Modified Ross operation with reinforcement of the pulmonary autograft: sixyear results. J Thorac Cardiovasc Surg. 2010;139:1420-3.

5. Slater M, Shen I, Welke K, Komanapalli C, Ungerleider R. Modification to the Ross procedure to prevent autograft dilatation. Semin Thorac Cardiovasc Pediatr Card Surg Annu. 2005;181-4.

6. Koul B, Al-Rashidi F, Bhat M, Meurling C. A modified Ross operation to prevent pulmonary autograft dilatation. Eur J Cardiothorac Surg. 2007;31:127-8.

7. Skillington PD, Mokhles MM, Takkenberg JJ, O'Keefe M, Grigg L, Wilson W, et al. Twenty-year analysis of autologous support of the pulmonary autograft in the Ross procedure. Ann Thorac Surg. 2013;96:823.

8. Skillington PD, Mokhles MM, Wilson W, Grigg L, Larobina M, O'Keefe M, et al. Inclusion cylinder method for aortic valve replacement utilising the Ross operation in adults with predominant aortic stenosis - $99 \%$ freedom from reoperation on the aortic valve at 15 years. Glob Cardiol Sci Pract. 2013;2013: 383-94.

9. Skillington PD, Grigg LE. Insertion of the pulmonary autograft as an inclusion cylinder - modifications to existing techniques. J Heart Valve Dis. 1995;4:374-8.

10. Skillington PD, Fuller JA, Grigg LE, Yapanis AG, Porter GF. Ross procedure. Inserting the autograft using a fully supported root replacement method; techniques and results. J Heart Valve Dis. 1999;8:593-600.

11. Kaplan EL, Meier P. Nonparametric estimation from incomplete observations. J Am Stat Assoc. 1958;53:457-81.

12. Mason DP, Mason DP, Rajeswaran J, Murthy SC, McNeill AM, Budev MM, et al. Spirometry after transplantation: how much better are two lungs than one? Ann Thorac Surg. 2008;85:1193-201. 201.e1-2.

13. Blackstone EH. Breaking down barriers: helpful breakthrough statistical methods you need to understand better. J Thorac Cardiovasc Surg. 2001;122: 430-9.

14. Diggle PJ, Heagerty PJ, Liang KY, Zeger SL. Analysis of Longitudinal Data. 2nd ed. New York: Oxford University Press; 2002.

15. Breiman L. Bagging predictors. Mach Learn. 1996;24:123-40.

16. Efron B, Tibshirani RJ. An Introduction to the Bootstrap. New York: Chapman and Hall/CRC; 1998.

17. Ross DN. Replacement of aortic and mitral valves with a pulmonary autograft. Lancet. 1967:2:956-9.

18. Charitos EI, Stierle U, Hanke T, Schmidtke C, Sievers H, Richardt D. Long-term results of 203 young and middle-aged patients with more than 10 years of followup after the original subcoronary Ross operation. Ann Thorac Surg. 2012;93: 495-502.

19. Stelzer P, Jones DJ, Elkins RC. Aortic root replacement with the pulmonary autograft. Circulation. 1989;5(Suppl III):209-13.

20. Elkins RC, Santagelo K, Steizer P, Randolph JD, Knott-Craig CJ. Pulmonary autograft replacement of the aortic valve: an evolution of techniques. J Card Surg. 1992; 7:108-16.

21. de Kerchove L, Rubay J, Pasquet A, Poncelet A, Ovaert C, Pirotte M, et al. Ross operation in the adult: long-term outcomes after root replacement and inclusion techniques. Ann Thorac Surg. 2009;87:95-102.

22. Klieverik LM, Takkenberg JJ, Bekkers JA, Roos-Hesselink JW, Witsenburg M, Bogers AJ. The Ross operation: a Trojan horse? Eur Heart J. 2007;28: 1993-2000.

23. Frigiola A, Ranucci M, Carlucci C, Giamberti A, Abella R, Di Donato M. The Ross procedure in adults: long-term followup and echocardiographic changes leading to pulmonary autograft reoperation. Ann Thorac Surg. 2008;86:482-9.

24. Elkins RC, Thompson DM, Lane MM, Elkins CC, Peyton MD. Ross operation: 16-year experience. J Thorac Cardiovasc Surg. 2008;136:623-30.

25. Elkins RC, Lane MM, McCue C. Pulmonary autograft re-operation: incidence and management. Ann Thorac Surg. 1996;62:450-5.

26. David TE, Omran A, Webb G, Rakowski H, Armstrong S, Zhao S. Geometric mismatch of the aortic and pulmonary roots causes aortic insufficiency after the Ross procedure. J Thorac Cardiovasc Surg. 1996;112:1231-9.

27. Klena JW, Shweiki E, Mahaffey HW, Woods EL, Benoit CH, Gilbert CL. Annuloplasty and aortoplasty as modifications of the Ross procedure for the correction of geometric mismatch. J Heart Valve Dis. 2000;9:195-9.

28. David TE, David C, Woo A, Manlhoit C. The Ross procedure: outcomes at 20 years. J Thorac Cardiovasc Surg. 2014;147:85-94. 